Check for updates

Cite this: Chem. Sci., 2017, 8, 5606

\title{
Imaging drug uptake by bioorthogonal stimulated Raman scattering microscopy $\dagger$
}

\author{
William J. Tipping, (DD ${ }^{\text {ab }}$ Martin Lee, (D) ${ }^{b}$ Alan Serrels, (D) $\dot{t}^{\mathrm{b}}$ Valerie G. Brunton (D) *b \\ and Alison N. Hulme (D) *a
}

Stimulated Raman scattering (SRS) microscopy in tandem with bioorthogonal Raman labelling strategies is set to revolutionise the direct visualisation of intracellular drug uptake. Rational evaluation of a series of Raman-active labels has allowed the identification of highly active labels which have minimal perturbation on the biological efficacy of the parent drug. Drug uptake has been correlated with markers of cellular composition and cell cycle status, and mapped across intracellular structures using dualcolour and multi-modal imaging. The minimal phototoxicity and low photobleaching associated with SRS microscopy has enabled real-time imaging in live cells. These studies demonstrate the potential for SRS microscopy in the drug development process.

Received 25th April 2017

Accepted 15th May 2017

DOI: $10.1039 / \mathrm{c} 7 \mathrm{sc} 01837 \mathrm{a}$

rsc.li/chemical-science

acquisition speeds. ${ }^{11}$ It has been widely used to study high-

\section{Introduction}

Visualising the complex interplay between bioactive small molecules and an intricate network of cellular machinery represents a major challenge within chemical biology, medical sciences and pharmaceutical development. ${ }^{1-4}$ Improving preclinical modelling studies, through integrating advanced imaging techniques into the early stages of drug-discovery campaigns, may also help reduce the high attrition rates of clinical drug candidates. ${ }^{5}$ Consequently, techniques which enable the direct visualisation of drug molecules in a nondestructive manner, and without the use of bioorthogonal ligation or antibody detection, represent an attractive prospect for biomedical and pharmaceutical research.

Spontaneous Raman microscopy enables the detection of molecular vibrations and has been applied to the direct visualisation of cells and their contents, ${ }^{6}$ and used for in vivo cancer diagnosis. ${ }^{7}$ Advances in microscope design and the development of stimulated Raman scattering (SRS) microscopy have delivered improved sensitivity, spectral resolution and imaging speeds. ${ }^{8-10}$ SRS allows sample visualisation and quantification based upon bond-specific chemical contrast, at up-to video-rate

${ }^{a}$ EaStCHEM School of Chemistry, The University of Edinburgh, Joseph Black Building, David Brewster Road, Edinburgh, EH9 3FJ, UK. E-mail: Alison.Hulme@ed.ac.uk ${ }^{b}$ Edinburgh Cancer Research Centre, Institute of Genetics and Molecular Medicine, The University of Edinburgh, Crewe Road South, Edinburgh, EH4 2XR, UK. E-mail: v. brunton@ed.ac.uk

$\dagger$ Electronic supplementary information (ESI) available: Fig. S1-S11, Table S1, Scheme S1, synthetic procedures and spectra for all labels and Raman-labelled anisomycin derivatives, drug uptake avi files. See DOI: 10.1039/c7sc01837a. Primary data files can be found at http://dx.doi.org/10.7488/ds/2046

\$ Current address: MRC Centre for Inflammation Research, Queens Medical Research Institute, The University of Edinburgh, 47 Little France Crescent, Edinburgh, EH16 4TJ, UK. concentration species within cells, including protein, ${ }^{12-14}$ lipids $^{15,16}$ and DNA. ${ }^{17,18}$ SRS microscopy in tandem with the

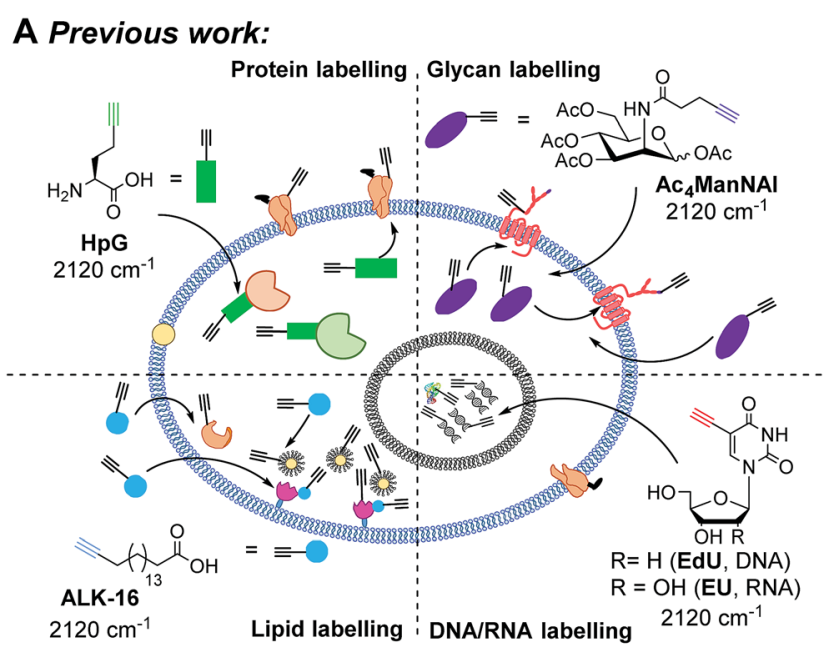

$X$ High local intracellular concentrations required $X$ Raman frequencies of alkynes overlap

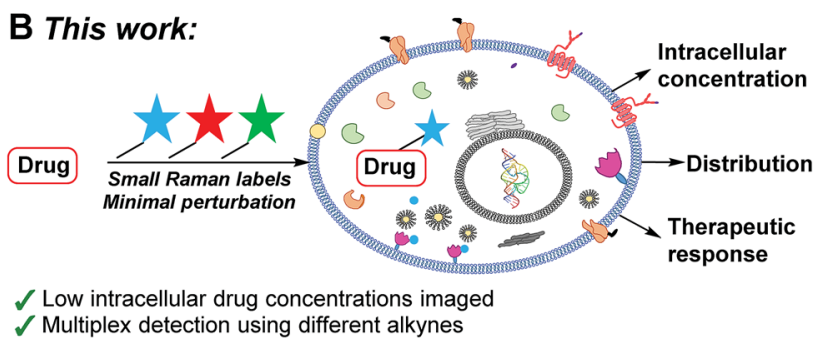

Fig. 1 Bioorthogonal Raman imaging approaches. (A) Raman imaging through metabolic incorporation of alkynes. (B) Multicolour SRS drug imaging with bioorthogonal (bis)alkyne labels. 
development of Raman labelling strategies looks set to play an important role as a new imaging modality to significantly enhance drug discovery and life-sciences research. ${ }^{19-23}$

Spectroscopically bioorthogonal labelling strategies, including alkyne-tag Raman imaging, have been proposed as an efficient route to bio-molecule visualisation by Raman microscopy (Fig. 1). ${ }^{24}$ Alkynes, and a number of other functional groups, generate Raman signals within the cellular silent region (1800-2800 $\mathrm{cm}^{-1}$ ), making them particularly attractive as labels. A limited number of spectroscopically bioorthogonal Raman labelled species, typically with high intracellular concentrations, have been visualised by Raman and SRS microscopy. ${ }^{25-29}$ This includes EdU (Fig. 1A), ${ }^{30}$ an alkynecontaining thymidine analogue, and the clinical drug, erlotinib. ${ }^{31}$ However, despite the potential which this technique clearly demonstrates, a unified approach to the successful imaging of drugs within cells using SRS microscopy is yet to be established. An analytical approach based on label design, biological validation, confirmation of cellular uptake and successful SRS imaging would allow SRS microscopy to be fully exploited in the drug development process.

\section{Results and discussion}

\section{Selection of Raman labels}

Small molecule visualisation by Raman microscopy requires a large Raman scattering cross section with minimal

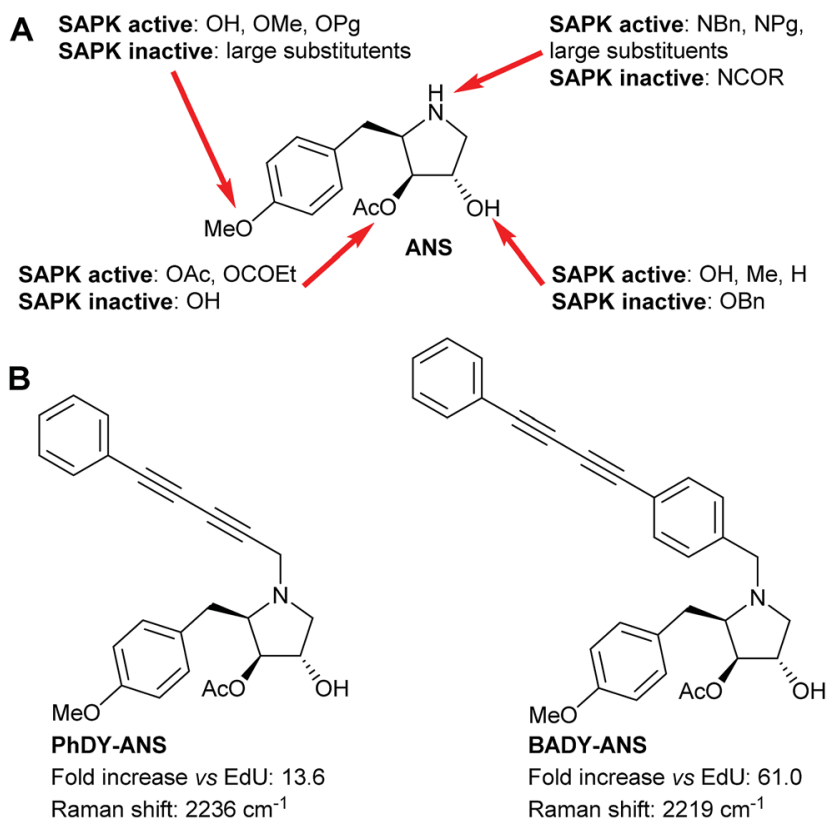

Fig. 2 Functionalisation of the anisomycin scaffold. (A) Summary of the known SAR for anisomycin (ANS) in SAPK activation studies (Pg indicates a propargyl group). (B) Labelled anisomycin derivatives used in this study: N-5-phenyl-2,4-pentadiyn-1-yl anisomycin (PhDY-ANS) and N-4-(4-phenyl-1,3-butadiyn-1-yl)benzyl anisomycin (BADYANS). Fold-increase vs. EdU represents the increase in Raman scattering activity of the Raman label compared to $\mathrm{EdU}(\mathrm{C} \equiv \mathrm{C})$ predicted by DFT calculation. Raman shifts of the solid material measured using the corresponding ·TFA salt. perturbation on the structure and dynamics of the conjugated small molecule. Rational prediction of Raman activity could greatly accelerate the design of labels for use in biological systems, and help to overcome current detection limits for the intracellular visualisation of small molecules. ${ }^{31}$ Density functional theory (DFT) calculations at the B3LYP/6-31G(d) level of theory have been used to aid the identification of drug metabolites within cells, ${ }^{31}$ whilst $a b$ initio calculations at the $\mathrm{HF}$ / $6311 \mathrm{G}(\mathrm{d})$ level have been used to predict the polarizability of alkyne and aryl alkyne groups. ${ }^{29}$ These previous studies have shown that increased conjugation within a poly-yne chain is concomitant with enhanced polarizability and hence an increase in Raman scattering cross section. ${ }^{32-34}$ Experimentally, the introduction of aryl end-capping groups can also improve the stability and shelf-life of poly-ynes. ${ }^{35-37}$ We sought to evaluate computationally a range of nitrile and alkynyl labels, which are both small and produce intense Raman bands in the cellular silent region (1800-2800 $\left.\mathrm{cm}^{-1}\right),,^{24,29}$ and to compare these results directly with experimentally determined values.

The bioactive small molecule anisomycin (ANS, Fig. 2) was identified as a suitable scaffold onto which spectroscopically bioorthogonal labels could be readily introduced with minimal functional perturbation, ${ }^{\mathbf{3 8 - 4 0}}$ allowing direct comparison between predicted and experimental Raman activity (Fig. S1 and Table S1†). To model the labels, DFT calculations using the B3LYP hybrid exchange-correlation functional, with the 6$31 \mathrm{G}(\mathrm{d}, \mathrm{p})$ double-zeta plus polarisation basis set, were used to predict the vibrational shift and Raman scattering activities $\left(I_{\text {Ram }}\right)$. For comparison, DFT calculations were also performed on EdU, which has previously been successfully imaged by SRS microscopy. ${ }^{25,26}$ As expected, these DFT calculations predicted an increase in the Raman scattering activity as the polarizability of the Raman label increased (Fig. S2A $\dagger$ ). A series of labelled anisomycin derivatives were prepared to validate these predictions (Scheme $\mathrm{S} 1 \dagger$ ), and the spontaneous Raman spectra were recorded of each (Fig. S3†). The experimental results show a high level of consistency with DFT predictions (Fig. S2B, S4†) and allowed the identification of two lead compounds (PhDYANS and BADY-ANS, Fig. 2) for use in this study.

\section{Assessment of biological activity}

Although the labels analysed by DFT generally have a much smaller $M_{\mathrm{W}}$ than traditionally used fluorophores and thus might be expected to have fewer effects on drug metabolism and pharmacokinetic properties (DMPK), ${ }^{41}$ they may still perturb the function of a drug under investigation. Initial biological screens for activity are typically conducted in the low (1-25 $\mu \mathrm{M})$ to mid (25-100 $\mu \mathrm{M})$ micromolar range, ${ }^{42}$ which correlates with the higher end of drug concentration ranges for plasma and extracellular fluid. ${ }^{43}$ Thus we sought to validate the biological efficacy of our labelled anisomycin derivatives at low micromolar concentrations.

Anisomycin is a potent inhibitor of protein synthesis and is known to activate the mitogen activated protein kinase pathways JNK/SAPK1 and p38/SAPK2 across a range of cell lines. ${ }^{44-46}$ Thus phosphorylation of JNK1/2 was used as a read-out of the 
A

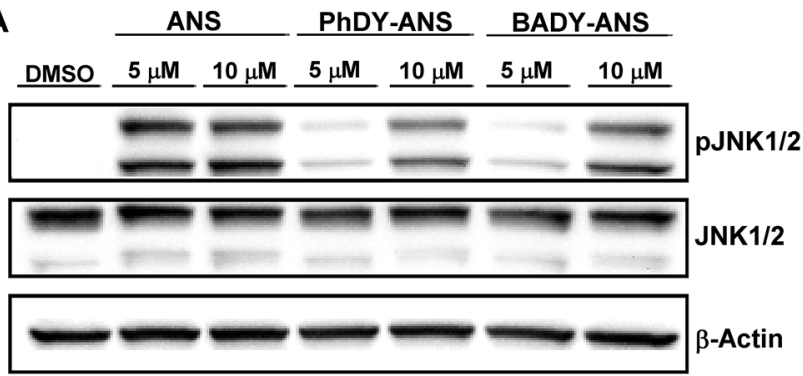

B

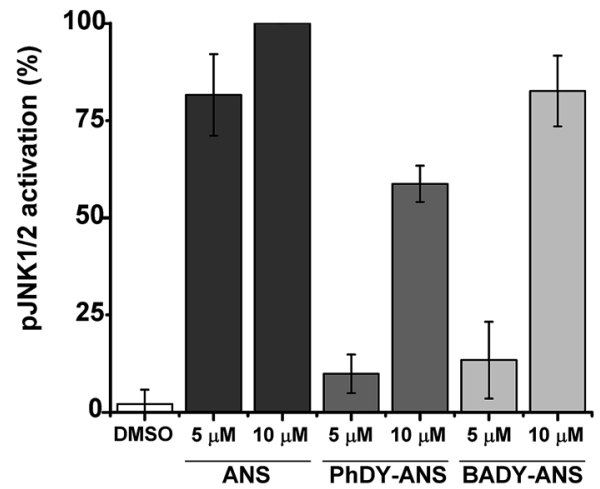

Fig. 3 Effects of anisomycin and Raman-labelled anisomycin derivatives, PhDY-ANS and BADY-ANS on the phosphorylation of JNK1/2 isoforms in SKBR3 cells. (A) SKBR3 cells were exposed to DMSO (lane 1); anisomycin (5 $\mu \mathrm{M}$, lane 2; $10 \mu \mathrm{M}$, lane 3); PhDY-ANS (5 $\mu \mathrm{M}$, lane 4; $10 \mu \mathrm{M}$, lane 5) and BADY-ANS (5 $\mu \mathrm{M}$, lane 6; $10 \mu \mathrm{M}$, lane 7). Western blot analysis was carried out with an antibody specific to phosphorylated JNK (pJNK1/2 at Thr183) and an antibody that recognises phosphorylated and unphosphorylated JNK1/2 equally well (JNK1/2). $\beta$-Actin was used as a loading control. (B) Quantification of the extent of JNK1/2 phosphorylation (pJNK1/2) in SKBR3 cells under the conditions described in (A). The pJNK1/2 activation levels in (A) were normalised to the pJNK1/2 activation observed with anisomycin (10 $\mu \mathrm{M}, 30 \mathrm{~min}$ ) which is expressed as 100\%. Error bars represent the standard deviation across $n=3$ repeats.

biological efficacy of anisomycin and its Raman-labeled derivatives. Anisomycin has shown activity against a number of breast cancer cell lines ${ }^{47-49}$ and phosphorylation of JNK1/2 in mammalian SKBR3 breast cancer cells was therefore selected as a suitable model. Time-course studies showed that maximal activation of JNK1/2 in SKBR3 cells by anisomycin was obtained at low micromolar concentrations within 30 minutes (Fig. S5A $\dagger$ ), and this activity was mirrored by all of the Ramanlabelled derivatives (Fig. S5B $\dagger$ ). Although PhDY-ANS and BADYANS gave reduced levels of activation at $5 \mu \mathrm{M}$ they were both shown to be active at $10 \mu \mathrm{M}$ (Fig. 3), indicating that they retain biological activity at the low micromolar concentrations typically used in screening assays.

\section{Raman spectral analysis and SRS microscopy of anisomycin derivatives}

Spontaneous Raman spectroscopy can be used to determine drug uptake, with studies on pelleted cells providing a useful initial screening platform. ${ }^{50}$ The local intracellular environment may affect the Raman vibrational frequency associated with

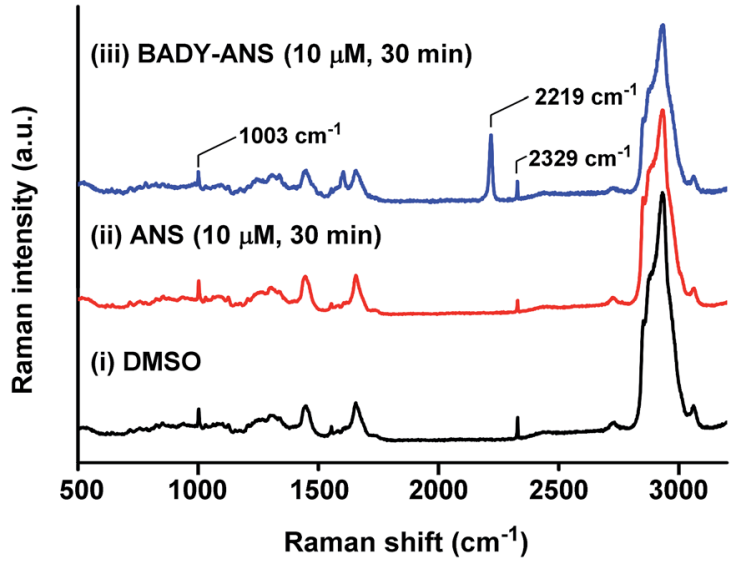

Fig. 4 Raman spectroscopy of SKBR3 cells treated with ANS and BADY-ANS. Representative spontaneous Raman spectrum recorded of a single fixed SKBR3 cell treated with (i) DMSO; (ii) ANS (10 $\mu \mathrm{M}, 30$ min) and (iii) BADY-ANS (10 $\mu \mathrm{M}, 30 \mathrm{~min})$. Raman spectra were normalised to the intensity of the peak at $1003 \mathrm{~cm}^{-1}$ (phenylalanine ring breathing mode), scaled between 0-35000 counts and offset for clarity. The following peaks have been annotated: $1003 \mathrm{~cm}^{-1}$ (phenylalanine ring breathing mode); $2219 \mathrm{~cm}^{-1}$ ( $\mathrm{C} \equiv \mathrm{C}, \mathrm{BADY}-\mathrm{ANS}$ ); $2329 \mathrm{~cm}^{-1}\left(\mathrm{~N}_{2}\right)$. $^{27,30}$ Raman spectra were acquired at $\lambda_{\mathrm{ex}}=532 \mathrm{~nm}$ for $10 \mathrm{~s}$ using a $50 \times$ objective.

bioorthogonal peaks; thus screening by spontaneous Raman spectroscopy enables rapid establishment of on- and off-target vibrational frequencies for subsequent SRS microscopy. SKBR3 cells were treated with the most Raman active derivative, BADY-ANS $(10 \mu \mathrm{M}, 30 \mathrm{~min})$ and washed; analysis of a treated cell revealed a clear peak indicative of BADY-ANS at $2219 \mathrm{~cm}^{-1}$, which is absent in the DMSO and anisomycin treated controls (Fig. 4). This supports both the cellular uptake of BADY-ANS, and that there was negligible change in the bioorthogonal Raman vibrational shift relative to that of the solid material ( $c f$. Table S1†).

Imaging using spontaneous Raman is time-consuming with typical acquisition times in excess of 30 minutes for a single cellmapping experiment. ${ }^{51}$ SRS offers up-to video-rate acquisition speeds, and hence is preferred for cellular imaging. ${ }^{11}$ In this study, SRS microscopy was performed on a custom-built microscope ${ }^{52}$ with optimum sensitivity achieved at speeds of $20 \mu$ s per pixel (which matches the longest time constant on the lock-in amplifier). This resulted in image acquisition times of less than 1 minute for a $1024 \times 1024$ frame, with pixel sizes ranging from $100 \mathrm{~nm} \times 100 \mathrm{~nm}$ to $1 \mu \mathrm{m} \times 1 \mu \mathrm{m}$ depending upon the field of view scanned. SKBR3 cells were treated with DMSO and ANS $(10 \mu \mathrm{M}, 30 \mathrm{~min})$ and SRS images were acquired by tuning the frequency difference between the pump and Stokes lasers to be resonant with intracellular components including proteins $\left(\mathrm{CH}_{3}\right.$, $2953 \mathrm{~cm}^{-1}$; amide I, $\left.1655 \mathrm{~cm}^{-1}\right)^{53}$ and lipids $\left(\mathrm{CH}_{2}, 2844 \mathrm{~cm}^{-1}\right) .^{54}$ False colours were applied to individual Raman spectral frequencies to allow the differentiation of intracellular components (Fig. 5A and B). This process allows cellular registration without the need for any additional labelling.

SRS images can contain background signals from competing pump-probe processes such as cross-phase modulation, 
A

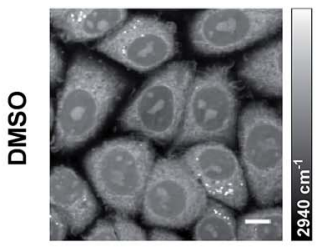

B

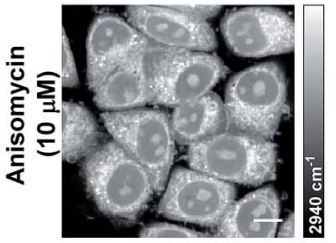

C.

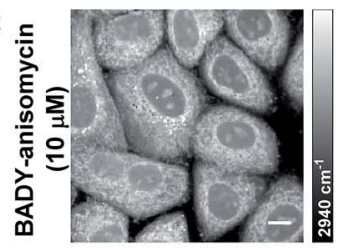

D
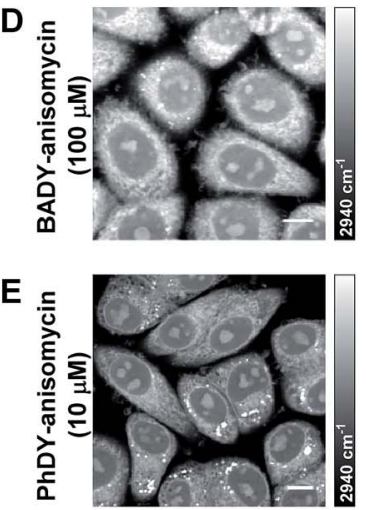

$\mathbf{F}$

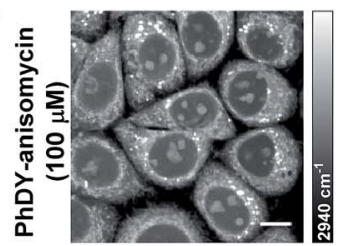

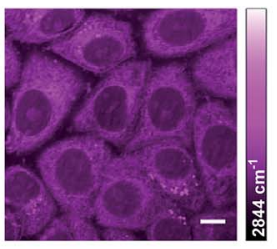
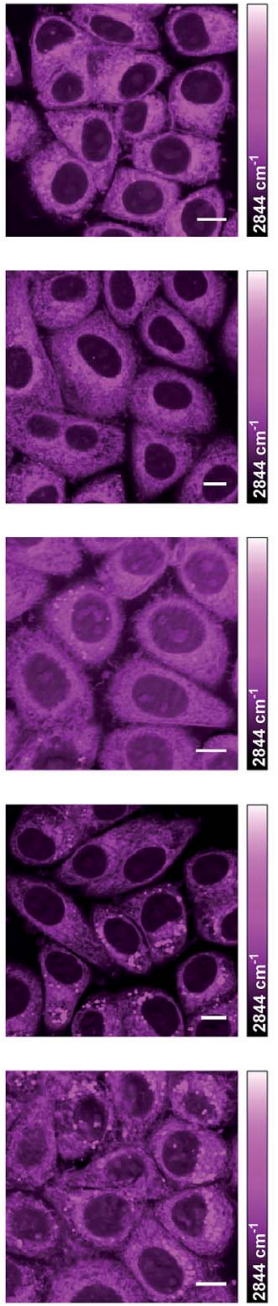
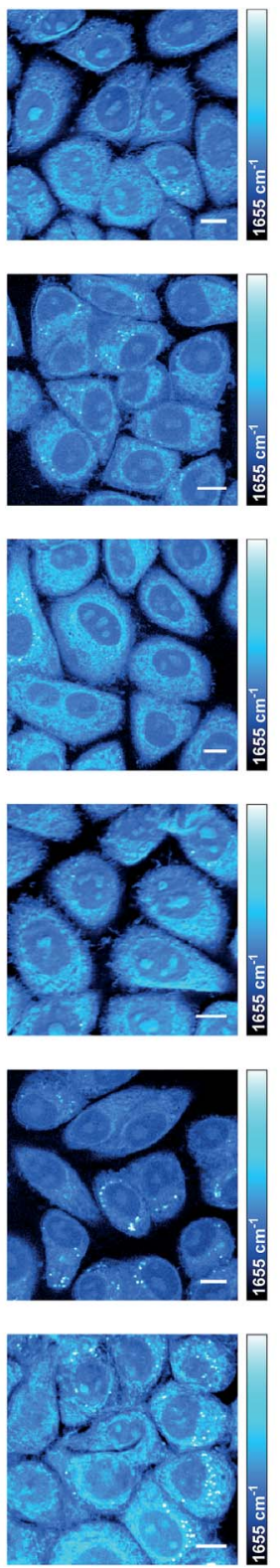
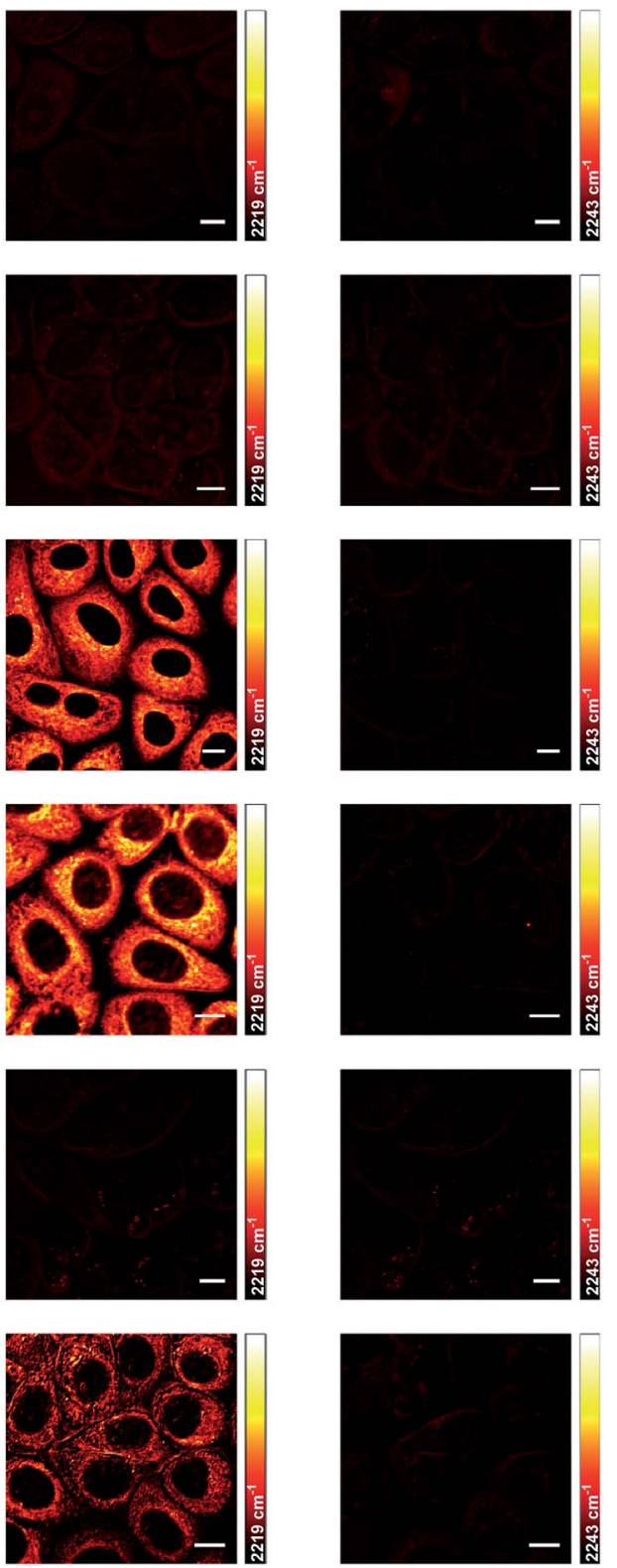

Fig. 5 Multicolour SRS imaging of fixed SKBR3 cells treated with ANS and its derivatives. SKBR3 cells were treated with: (A) DMSO; (B) ANS (10 $\mu$ M, $30 \mathrm{~min}) ;(\mathrm{C})$ BADY-ANS (10 $\mu \mathrm{M}, 30 \mathrm{~min}) ;(\mathrm{D})$ BADY-ANS (100 $\mu \mathrm{M}, 30 \mathrm{~min}) ;(\mathrm{E})$ PhDY-ANS (10 $\mu \mathrm{M}, 30 \mathrm{~min})$ and (F) PhDY-ANS (100 $\mu$ M, $30 \mathrm{~min})$. Images were acquired in sequence at (i) $2940 \mathrm{~cm}^{-1}\left(\mathrm{CH}_{3}\right.$, proteins); (ii) $2844 \mathrm{~cm}^{-1}$ ( $\mathrm{CH}_{2}$, lipids); (iii) $1655 \mathrm{~cm}^{-1}$ (amide-I, proteins); (iv) $2219 \mathrm{~cm}^{-1}$ (C $\equiv$ C, PhDY-/BADY-ANS); $2243 \mathrm{~cm}^{-1}$ (cell-silent region). Images acquired at $1024 \times 1024$ pixels, $20 \mu$ s pixel dwell time with false colours applied to different detection wavenumbers. Scale bars: $10 \mu \mathrm{m}$.

transient absorption and photothermal effects. ${ }^{55}$ Re-tuning the pump wavelength by a few nanometers allows off-resonance images to be acquired (at a difference of $10-20 \mathrm{~cm}^{-1}$ from the on-resonance image), which can be used to distinguish true SRS signals from these artefacts. ${ }^{55}$ Tuning to the spectroscopically bioorthogonal region of these cellular images (Fig. 5A and B) showed there was minimal SRS signal detected at either $2219 \mathrm{~cm}^{-1}$ (C $\equiv \mathrm{C}$ BADY-ANS on resonance) or $2243 \mathrm{~cm}^{-1}$ (cellsilent region), indicating that any signals detected in this region can be assigned to the Raman-labelled species with confidence. Subsequently SKBR3 cells were treated with BADY-ANS $(10 \mu \mathrm{M}, 30 \mathrm{~min})$, washed and fixed for imaging.
Tuning to the bioorthogonal region of the Raman spectrum enabled detection of BADY-ANS (alkyne, $2219 \mathrm{~cm}^{-1}$; offresonance, $2243 \mathrm{~cm}^{-1}$ ) which distributes throughout the cytoplasm of the cell (Fig. 5C), and is especially pronounced in regions surrounding the nucleus.§ The off-resonance image at $2243 \mathrm{~cm}^{-1}$, where no Raman transition occurs, demonstrates the non-resonant background free nature of SRS microscopy. SKBR3 cells treated at higher BADY-ANS concentrations $(100 \mu \mathrm{M}, 30 \mathrm{~min})$ showed a similar intracellular distribution of labelled drug (Fig. 5D) to those treated at the lower concentration. DFT calculations predicted that PhDY-ANS would have a reduced Raman scattering cross section (Table S1 $\dagger$ ) and when 

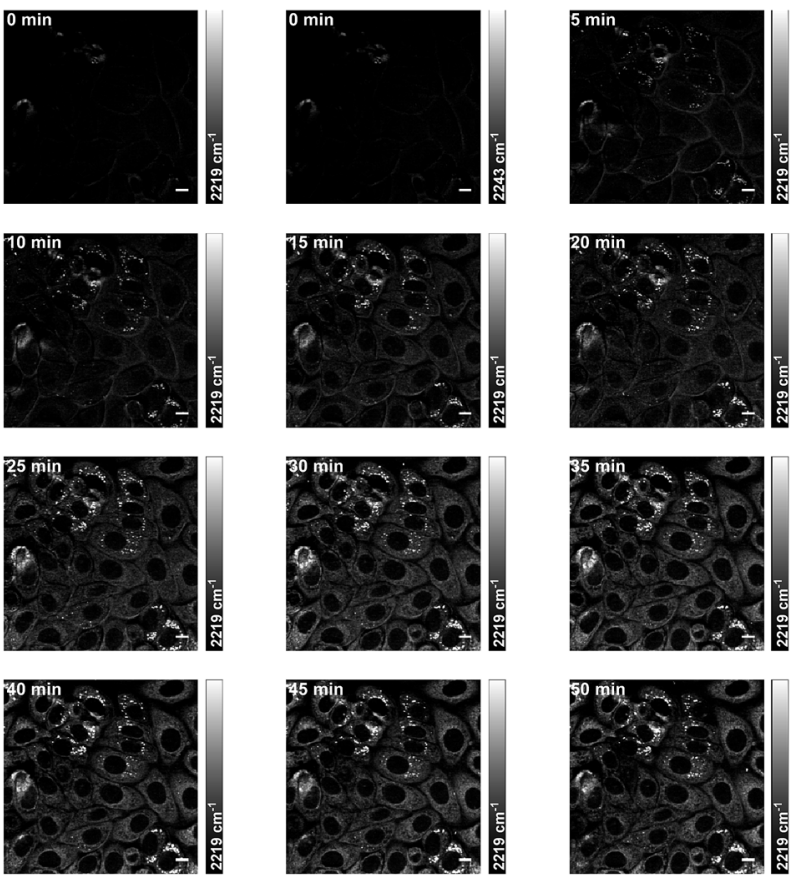

by more than 50 -fold from the dosing concentrations used $(10 \mu \mathrm{M})$. These results highlight the potential that this method has for probing mechanistic aspects of cellular drug uptake.

\section{Multi-modal and dual-colour imaging in live cells}

Live cell imaging of drug accumulation would enable studies correlating drug uptake and subcellular localisation with downstream phenotypic markers such as changes to cellular composition and cell cycle progression. ${ }^{56}$ To demonstrate the potential of SRS microscopy to visualise drug uptake and retention, time-resolved imaging of BADY-ANS uptake into live cells was performed. SKBR3 cells were treated with BADY-ANS (10 $\mu \mathrm{M}$ at $t=0 \mathrm{~min}$ ), and an on-resonance SRS image (at $2219 \mathrm{~cm}^{-1}$ ) was acquired every minute at $20 \mu \mathrm{s}$ per pixel, for 60 minutes (Fig. 6, ESI $\dagger$ Movie BADY-ANS). Intracellular BADY-ANS is detectable within 5 min suggesting rapid accumulation of the drug within cells, and it appears as locally concentrated bright spots within $10 \mathrm{~min}$ which persist through to 60 minutes.

Off-resonance images acquired at 0 and 60 minutes suggest that there is no localised sample damage due to prolonged image acquisition under these conditions (Fig. 6). Furthermore, the lack of any detectable signal (at $2219 \mathrm{~cm}^{-1}$ ) in time-lapse images of ANS uptake over 60 minutes at equivalent dosing levels (Fig. S7, ESI $\dagger$ Movie ANS) indicates that the increase in signal observed in Fig. 6 is a direct result of BADY-ANS uptake, rather than the emergence of any parasitic signals. The signal intensity afforded by the BADY label means that SRS images can be acquired at much faster acquisition times if needed, and at speeds which are unobtainable using conventional spontaneous Raman spectroscopy. Images of SKBR3 cells incubated with BADY-ANS at the higher dosing concentration $(100 \mu \mathrm{M}$, $20 \mathrm{~min}$ ) could be obtained in under $1 \mathrm{~s}$ using acquisition times of $2 \mu$ s per pixel $(512 \times 512$ frame, Fig. S8 $\dagger)$. $\uparrow$ These real-time images highlight the applicability of Raman-labels to drug uptake studies and demonstrate the minimal phototoxicity
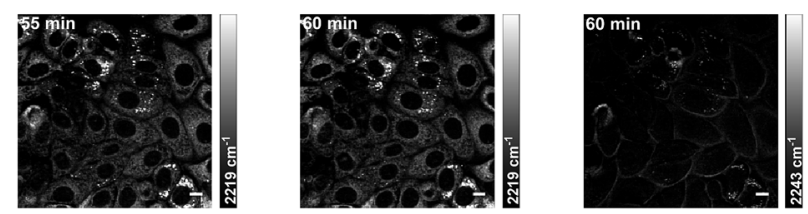

Fig. 6 Time-lapse imaging of BADY-ANS uptake into live SKBR3 cells. SKBR3 cells were treated with BADY-ANS $(10 \mu \mathrm{M}$ at $t=0 \mathrm{~min})$ and imaged at $2219 \mathrm{~cm}^{-1}$ (C $\equiv C$, BADY-ANS) every minute for $60 \mathrm{~min}$. Offresonance images were acquired at $2243 \mathrm{~cm}^{-1}$ (cell-silent region) at $t=0 \mathrm{~min}$ and $t=60 \mathrm{~min}$. Images were acquired at $1024 \times 1024$ pixels, $20 \mu$ s pixel dwell time. Scale bars: $10 \mu \mathrm{m}$

resulting from SRS imaging conditions. They also show that in contrast to fluorescence microscopy, where photostability can represent a major experimental challenge, Raman labels show minimal photobleaching. ${ }^{57}$

Using a dual-colour approach, an overlay of images acquired for lipid $\mathrm{CH}_{2}\left(2844 \mathrm{~cm}^{-1}\right)$ and BADY-ANS $\left(2219 \mathrm{~cm}^{-1}\right)$ at 30 minutes (Fig. S9†) suggests that in some cells the drug is initially concentrated in lipid droplets; however, a very heterogeneous uptake is observed across the focal field. Using a multimodal approach to investigate this further, SKBR3 cells were treated simultaneously with BADY-ANS $(10 \mu \mathrm{M}, 30 \mathrm{~min})$ and ERTracker Green ( $1 \mu \mathrm{M}, 30 \mathrm{~min})$, a cell-permeable fluorescent stain selective for the endoplasmic reticulum (Fig. 7). In the control experiment, cells treated with the DMSO vehicle and ER Tracker green (Fig. 7A) showed no SRS signal at either $2219 \mathrm{~cm}^{-1}(\mathrm{C} \equiv \mathrm{C}$ BADY-ANS on-resonance) or $2243 \mathrm{~cm}^{-1}$ (cell-silent region), indicating that there is no interference in the SRS images arising from the presence of the fluorophore. In the BADY-ANS treated cells (Fig. 7B), the Raman-labelled drug is co-localised with ER-Tracker Green in the merged images, which is in agreement with its known binding to the 60S ribosomal 

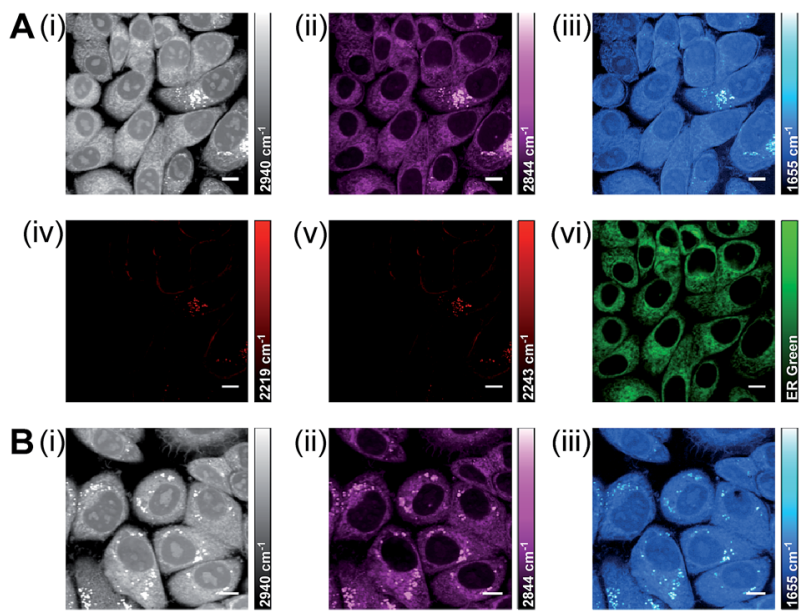

(iv)
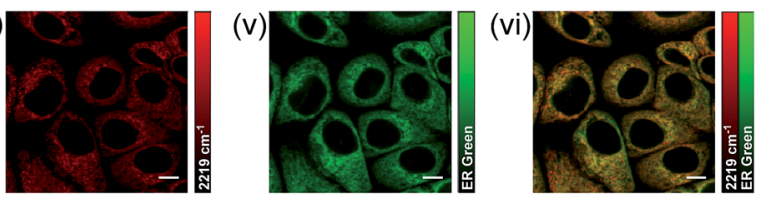

(vii)
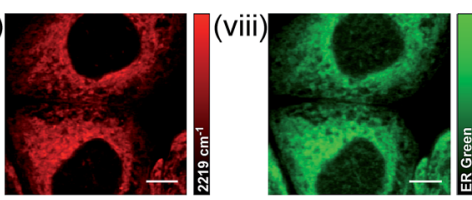

(ix)

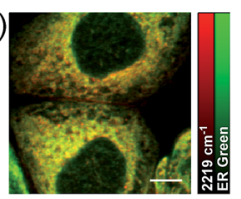

$(\mathrm{x})$

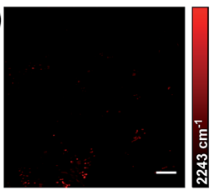

Fig. 7 Multi-modal imaging to determine the intracellular location of BADY-ANS. (A) SKBR3 cells were treated with DMSO and ER Tracker Green ( $1 \mu \mathrm{M}, 30 \mathrm{~min}$ ) before washing and fixing. SRS images were acquired at (i) $2940 \mathrm{~cm}^{-1}$ ( $\mathrm{CH}_{3}$, proteins); (ii) $2844 \mathrm{~cm}^{-1}\left(\mathrm{CH}_{2}\right.$, lipids); (iii) $1655 \mathrm{~cm}^{-1}$ (amide-l, proteins); (iv) $2219 \mathrm{~cm}^{-1}$ (C $\equiv \mathrm{C}, \mathrm{BADY}-\mathrm{ANS}$ ); (v) $2243 \mathrm{~cm}^{-1}$ (cell-silent region); (vi) Two-photon fluorescence (TPF) image (ER Tracker Green). (B) SKBR3 cells were treated with BADYANS $(10 \mu \mathrm{M}, 30 \mathrm{~min})$ and ER Tracker Green $(1 \mu \mathrm{M}, 30 \mathrm{~min})$ before washing and fixing. SRS images were acquired at (i) $2940 \mathrm{~cm}^{-1}\left(\mathrm{CH}_{3}\right.$, proteins); (ii) $2844 \mathrm{~cm}^{-1}\left(\mathrm{CH}_{2}\right.$, lipids); (iii) $1655 \mathrm{~cm}^{-1}$ (amide-l, proteins); (iv) and (vii) $2219 \mathrm{~cm}^{-1}$ (C $\equiv$ C, BADY-ANS); and (x) $2243 \mathrm{~cm}^{-1}$ (cell-silent region); (v) and (viii) TPF image (ER Tracker Green); (vi) merge of images acquired in (iv) and (v); (ix) merge of images acquired in (vii) and (viii). SRS images acquired at $1024 \times 1024$ pixels, $20 \mu$ s pixel dwell time with false colours applied to different detection wavenumbers. TPF images $\lambda_{\mathrm{ex}}=860.8 \mathrm{~nm}$ and $1064 \mathrm{~nm}$. Scale bars: $10 \mu \mathrm{m}$.

subunit. ${ }^{44}$ These studies show that SRS microscopy allows rapid, non-destructive, high-resolution imaging of drug uptake in living cells which can be readily augmented using dual-colour and multi-modal approaches to follow accumulation into intracellular structures.

Image acquisition at wavenumbers resonant with intracellular components allows drug-induced changes in cellular composition to be analysed, which may help define the drug mechanism of action. The protein $\mathrm{CH}_{3}$ peak $\left(2940 \mathrm{~cm}^{-1}\right)$ has been used to distinguish between necrotic and healthy tissues and also for the detection of tumor margins. ${ }^{58,59}$ However, such changes in global protein content will not occur following acute drug administration. In contrast, the dynamic nature of lipid droplet assembly and disassembly, ${ }^{60,61}$ means that quantification of short term drug-induced changes in lipid droplets is possible. SKBR3 cells were treated $(10 \mu \mathrm{M}, 30 \mathrm{~min})$ with either ANS or BADY-ANS and the lipid $\mathrm{CH}_{2}$ peak $\left(2844 \mathrm{~cm}^{-1}\right)$ was used to determine changes in the number of lipid droplets across the respective cell populations (Fig. S10†). There was a small reduction in the number of lipid droplets following treatment with ANS and BADY-ANS compared to DMSO controls, but further mechanistic studies will be required to determine the biological significance of these findings. That both ANS and BADY-ANS resulted in the same reduction in lipid droplet number provides further evidence that the BADY label does not alter the biological activity of anisomycin.

As well as providing information about the spatial distribution of drug uptake, a dual-colour SRS approach might also be used to correlate drug uptake with markers of cell cycle progression. EdU (Fig. 1) is a thymidine analogue widely used as a probe for DNA synthesis in proliferating cells through the CuAAC conjugation of fluorophores; ${ }^{62}$ and its detection has recently been achieved by Raman microscopy. ${ }^{30}$ Detection of EdU and BADY-ANS would demonstrate the potential application of SRS microscopy to this field. SKBR3 cells were serumstarved to synchronise the cell population in the G0 phase of the cell cycle, then treated with EdU $(100 \mu \mathrm{M}, 18 \mathrm{~h})$ in serum containing medium to stimulate DNA synthesis, before washing and treatment with BADY-ANS $(10 \mu \mathrm{M}, 30 \mathrm{~min})$. Intracellular uptake of both molecules was confirmed by the presence of two peaks (at $2120 \mathrm{~cm}^{-1}$ EdU and $2219 \mathrm{~cm}^{-1}$ BADY-ANS) in the spontaneous Raman spectrum of a pellet of treated cells (Fig. S11†). Multicolour SRS microscopy allowed the detection of intracellular protein $\left(\mathrm{CH}_{3}, 2953 \mathrm{~cm}^{-1}\right.$; amide-I, $\left.1655 \mathrm{~cm}^{-1}\right)$, lipid $\left(\mathrm{CH}_{2}, 2844 \mathrm{~cm}^{-1}\right)$, BADY-ANS $\left(\mathrm{C} \equiv \mathrm{C}, 2219 \mathrm{~cm}^{-1}\right)$ and EdU $\left(\mathrm{C} \equiv \mathrm{C}, 2120 \mathrm{~cm}^{-1}\right.$ ) in a single cell (Fig. 8). Remarkably, despite the lower Raman scattering activity afforded by the bioorthogonal alkyne of EdU as predicted by DFT (Fig. S2A $\dagger$ ), it is possible to detect it by SRS microscopy. This suggests that the high intra-nuclear concentration of EdU compensates for its lower Raman scattering activity, enabling its detection by SRS within the cell. Merging the image acquired for BADY-ANS (at $2219 \mathrm{~cm}^{-1}$ ) and EdU (at $2120 \mathrm{~cm}^{-1}$ ), allows simultaneous assessment of the intracellular drug concentration and cell cycle status (Fig. 8). This demonstrates the potential of this approach for identifying drug dependent changes in cell cycle progression at the single cell level, which is an important advance in the drug development process.

\section{Application to the investigation of combination therapies}

The use of combination therapies is an area of increasing interest in drug discovery; ${ }^{63-65}$ assessment of the individual effects of drugs (often with differential rates of uptake) on cell populations in combined doses represents a major challenge. ${ }^{66}$ Here we demonstrate the power of dual-colour alkyne-label imaging by SRS microscopy using bespoke alkyne-derived 

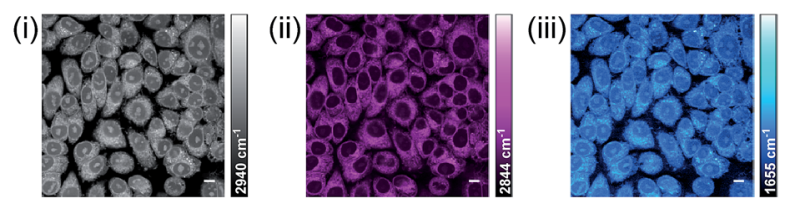

(iv)
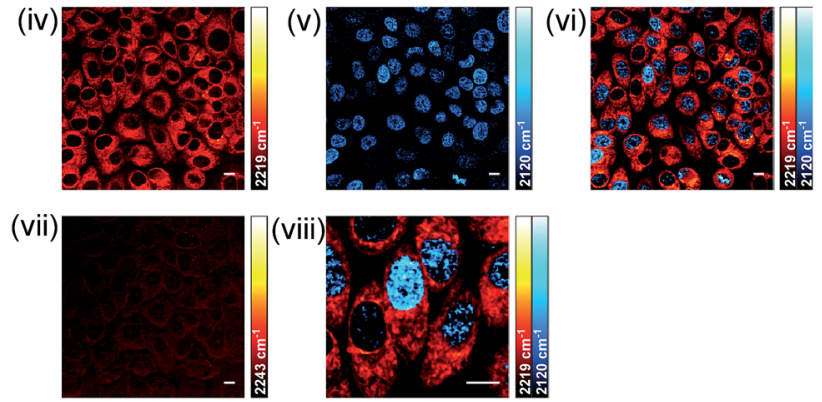

Fig. 8 Dual-colour alkyne-label imaging by SRS microscopy. SKBR3 cells were treated with EdU $(100 \mu \mathrm{M}, 18 \mathrm{~h})$ and BADY-ANS $(10 \mu \mathrm{M}$, $30 \mathrm{~min}$ ), washed and fixed prior to imaging. SRS images acquired at (i) $2940 \mathrm{~cm}^{-1}\left(\mathrm{CH}_{3}\right.$, proteins); (ii) $2844 \mathrm{~cm}^{-1}\left(\mathrm{CH}_{2}\right.$, lipids); (iii) $1655 \mathrm{~cm}^{-1}$ (amide-I, proteins); (iv) $2219 \mathrm{~cm}^{-1}$ (C $\equiv$ C, BADY-ANS); (v) $2120 \mathrm{~cm}^{-1}$ ( $\mathrm{C} \equiv \mathrm{C}, \mathrm{EdU}$ ); (vi) overlay of images acquired in (iv) and (v); (vii) $2243 \mathrm{~cm}^{-1}$ (cell-silent region); (viii) expanded view of image presented in (vi). Images acquired at $1024 \times 1024$ pixels, $20 \mu$ s pixel dwell time with false colours applied to different detection wavenumbers. Scale bars: $10 \mu \mathrm{m}$

Raman labels as a potential solution to this challenge. Accumulation of a drug within cells can range from a high local concentration, as with EdU, to a more diffuse distribution, as illustrated for BADY-ANS. Since the signal intensity achieved is directly related to this local concentration, this is an important consideration in the choice of label used for Raman imaging. Drugs with a more diffuse distribution thus require the use of a higher intensity label (BADY or PhDY) to enable effective imaging. Selecting two appropriate Raman labels based on DFT predictions (Table $\mathrm{S} 1 \dagger$ ) would enable rapid experimental design. While further label development could extend the current spectroscopic pallet to enable greater opportunities for multiplex detection in SRS imaging.

\section{Conclusions}

The outstanding biocompatibility of SRS microscopy is set to revolutionise our ability to probe intracellular biological processes. This study describes the rational evaluation of a selection of spectroscopically bioorthogonal labels for SRS microscopy, allowing two functionally-active lead derivatives (PhDY-ANS and BADY-ANS) to be selected for study. The subcellular localisation of the most Raman active derivative, BADY-ANS, has been determined using dual-colour and multi-modal imaging approaches. The simultaneous detection of BADY-ANS together with either lipid droplets or EdU, demonstrates the potential of dual-colour SRS microscopy for identifying drugdependent changes in cellular composition and cell cycle progression at the single cell level. Time-resolved detection of the uptake of BADY-ANS into live cells highlights the biocompatibility of this technique. On-going improvements to microscope design and optics, combined with the development of bespoke spectroscopically bioorthogonal labels, ensure that the future is bright for this imaging modality.

\section{Experimental}

\section{Computational methods}

The geometries of compounds evaluated in Table S1 and Fig. S2 $\uparrow$ were optimised at the B3LYP/6-31G(d,p) level of theory in the gas phase, using the Gaussian 09 programme. Vibrational frequencies and Raman scattering activities, obtained from the polarizability derivatives, were calculated analytically.

\section{Cell culture}

Human breast cancer cell line SKBR3 was purchased from the American Type Culture Collection, and maintained in Dulbecco's modified Eagle's medium (DMEM, Sigma-Aldrich) supplemented with $2 \mathrm{mM}$ L-glutamine, $1 \%$ penicillin-streptomycin and $10 \%$ foetal bovine serum (all Thermo Fisher Scientific) at $37{ }^{\circ} \mathrm{C}$ in a humidified atmosphere containing $5 \% \mathrm{CO}_{2}$. For experiments using EdU (Thermo Fisher Scientific) cells grown under these normal conditions were synchronized in G0 by serum starvation, where the $10 \%$ FBS containing medium was removed and cells were cultured in medium containing $0.1 \%$ FBS for $24 \mathrm{~h}$, prior to EdU treatment in $10 \%$ serum-containing DMEM.

\section{Western blotting}

Cells were treated with ANS (Abcam) or Raman-labelled derivatives as indicated in the figure legend. Cells were washed with ice-cold PBS and subsequently lysed in RIPA buffer supplemented with cOmplete ${ }^{\mathrm{TM}}$ ULTRA protease inhibitor and PhosSTOP phosphatase inhibitor cocktails (Roche). Cleared lysates were resolved by SDS-PAGE. Primary antibodies used for Western blotting were as follows: phosphoJNK1/2 (Thr183/ Tyr185; $1: 1000)$, JNK1/2 $(1: 1000)$ and $\beta$-Actin $(1: 3000)$ (all Cell Signaling Technologies).

\section{Spontaneous Raman spectroscopy}

The spontaneous Raman spectra were acquired using a confocal Raman spectrometer (inVia Raman microscope, Renishaw) at room temperature. A $297 \mathrm{~mW}$ (206 mW after objective) $785 \mathrm{~nm}$ diode laser or a $200 \mathrm{~mW} 532 \mathrm{~nm}$ laser excitation source was used to excite the sample through a $50 \times$, N.A. 0.75 objective (Leica Biosystems). The recorded spectral range for grating $1200 \mathrm{~g} \mathrm{~mm}^{-1}$ was $100-3200 \mathrm{~cm}^{-1}$. The total data acquisition was performed during $60 \mathrm{~s}$ for spectra recorded at $\lambda_{\mathrm{ex}}=785 \mathrm{~nm}$ or $10 \mathrm{~s}$ for spectra recorded at $\lambda_{\mathrm{ex}}=532 \mathrm{~nm}$ using the WiRE software. All of the spectra acquired at $\lambda_{\mathrm{ex}}=785 \mathrm{~nm}$ were background subtracted using a background correction algorithm as described previously, ${ }^{67}$ whilst those acquired at $\lambda_{\mathrm{ex}}=532 \mathrm{~nm}$ are uncorrected.

\section{Two-photon fluorescence and stimulated Raman scattering (SRS) microscopy}

Images were acquired using a custom-built multi-modal microscope setup. A picoEmerald (APE, Berlin, Germany) laser 
provided both a tunable pump laser $(720-990 \mathrm{~nm}, 7 \mathrm{ps}, 80 \mathrm{MHz}$ repetition rate) and a spatially and temporally overlapped Stokes laser (1064 nm, 5-6 ps, $80 \mathrm{MHz}$ repetition rate). The output beams were inserted into the scanning unit of an Olympus FV1000MPE microscope using a series of dielectric mirrors and a $2 \times$ lens based beam-expanding module. The resulting $2.4 \mathrm{~mm}$ beams were expanded by a further $3.6 \times$ lens within the microscope and directed into an Olympus XLPL25XWMP N.A. 1.05 objective lens using a short-pass $690 \mathrm{~nm}$ dichroic mirror (Olympus). The objective was under filled to achieve higher power transmissions through the microscope which were shown to be essential to detect the SRS signal. Backscattered emission signals from two-photon fluorescence was separated from any backscattered excitation light using a short-pass $690 \mathrm{~nm}$ dichroic mirror and IR cut filter (Olympus). A series of filters and dichroic mirrors were then used to deconvolve the different emission signals onto one of 4 available photo-multiplier tubes (PMT). ER-Tracker Green twophoton fluorescence signals were filtered using FF552-Di02, FF483/639-Di01 and FF510/84 (Semrock).

For SRS measurements, the Stokes beam was modulated with a $20 \mathrm{MHz}$ EoM built into the picoEmerald. Forward scattered light was collected by a $20 \times$ Olympus XLUMPLFLN N.A. 1.00 objective lens and Stokes light was removed by filtering with an ET890/220m filter (Chroma). A telescope focused the light onto an APE silicon photodiode connected to an APE lock in amplifier with the time constant set to $20 \mu$ s except for fast acquisitions where it was set to $2 \mu$ s. The lock in amplifier signal was fed into an Olympus FV10-Analog unit.

Laser powers after the objective were measured up to 40-70 $\mathrm{mW}$ for the pump laser and up to $70 \mathrm{~mW}$ for the Stokes laser. All images were recorded at $512 \times 512$ or $1024 \times 1024$ pixels with a pixel dwell time between 2 and $20 \mu$ s, using FluoView FV10-ASW scanning software (Olympus).

\section{Sample preparation for spontaneous Raman spectroscopy}

SKBR3 cells were treated with BADY-ANS $(10 \mu \mathrm{M}, 30 \mathrm{~min})$, ANS $(10 \mu \mathrm{M}, 30 \mathrm{~min})$ or DMSO $(1: 1000,30 \mathrm{~min})$ and then washed with PBS prior to fixing with formaldehyde $(3.7 \%$ in $\mathrm{PBS}$, $\left.10 \mathrm{~min}, 37^{\circ} \mathrm{C}\right)$. The cells were washed with PBS $(2 \times)$ prior to analysis of a single cell by spontaneous Raman spectroscopy at $\lambda_{\mathrm{ex}}=532 \mathrm{~nm}$. For analysis of EdU incorporation into newlysynthesised DNA, SKBR3 cells were serum starved for $24 \mathrm{~h}$ prior to treatment with EdU $(100 \mu \mathrm{M}, 18 \mathrm{~h})$ in serum-containing DMEM followed by treatment with BADY-ANS $(100 \mu \mathrm{M}, 20 \mathrm{~min})$, before washing with PBS prior to trypsinisation and diluted with DMEM. The resulting cell suspension was centrifuged at $175 g$ and the cell pellet washed with DMEM/PBS $(1 / 1 \mathrm{v} / \mathrm{v} ; 10 \mathrm{~mL})$ and re-centrifuged $(2 \times)$. The cell pellet was transferred to $\mathrm{CaF}_{2}$ coverslips for analysis by spontaneous Raman spectroscopy using $\lambda_{\mathrm{ex}}=785 \mathrm{~nm}$.

\section{Sample preparation for SRS microscopy}

For all SRS imaging experiments, SKBR3 cells were first seeded into Fluorodish Cell Culture Dishes (World Precision Instruments) with a density of $1 \times 10^{5}$ cells per dish with $2 \mathrm{~mL}$ DMEM culture medium for $20 \mathrm{~h}$. Details of the dosing concentrations and dosing times are provided in the figure legends. Where indicated, cells were fixed with formaldehyde $(3.7 \%$ in PBS, $\left.10 \mathrm{~min}, 37^{\circ} \mathrm{C}\right)$ and washed with PBS $(3 \times 2 \mathrm{~mL})$ before imaging. For multi-modal imaging experiments with ER-Tracker, SKBR3 cells were treated with ER-Tracker Green (BODIPY® TR Glibenclamide, Thermo Fisher Scientific) ( $1 \mu \mathrm{M}, 30 \mathrm{~min})$ and BADY-ANS $(10 \mu \mathrm{M}, 30 \mathrm{~min})$, washed with PBS $(3 \times 2 \mathrm{~mL})$, fixed $(3.7 \%$ formaldehyde in PBS, $\left.2 \mathrm{~min}, 37^{\circ} \mathrm{C}\right)$, washed with PBS $(3 \times 2 \mathrm{~mL}$; $5 \mathrm{~min}$ ) and imaged by SRS microscopy and two-photon microscopy. For analysis of EdU incorporation into newly synthesised DNA, SKBR3 cells were serum starved for $24 \mathrm{~h}$, prior to treatment with EdU $(100 \mu \mathrm{M}, 18 \mathrm{~h})$ in serum-containing DMEM followed by treatment with BADY-ANS $(10 \mu \mathrm{M}, 30 \mathrm{~min})$ and fixed.

\section{Image analysis}

False colour assignments, overlays and scale bars were added to images using ImageJ. Consistent brightness settings were used throughout. For the analysis of lipid droplets: a z-stack across a typical field of view ( $\sim 40$ cells, $25 \times$ objective lens) was acquired for each treatment condition and a maximum intensity projection was created ( $n=9$ for each condition). The number of lipid droplets $>1 \mu \mathrm{m}$ were counted using threshold analysis with the droplet_counter.jar application on ImageJ. For real-time imaging: frames were acquired at minute intervals and were compiled using ImageJ using consistent brightness settings throughout. Movies are supplied as avi files in the ESI. $\dagger$

\section{Acknowledgements}

This work was supported by Cancer Research UK (grants C157/ A12753, C10195/A18075 and C157/A15703), the BBSRC (grant BB/N021614/1), the European Research Council Advanced Investigator Grant (grant number 294440), the Scottish Power Strategic Alliance Framework and the Clerk Maxwell Cancer Fund. We thank Dr David Rogers and Dr Sarah McAughtrie of the School of Chemistry, University of Edinburgh for helpful discussions.

\section{Notes and references}

$\S$ This is consistent with the distribution observed by fluorescence microscopy upon incubation of HEK-293 cells with $N$-linked dansyl-anisomycin $(109 \mu \mathrm{M}, 30$ min): see ref. 38 .

I Acquisition speed limited by the microscope rather than signal intensity.

1 J. A. Prescher and C. R. Bertozzi, Nat. Chem. Biol., 2005, 1, 1321.

2 J. S. Cisar and B. F. Cravatt, J. Am. Chem. Soc., 2012, 134, 10385-10388.

3 N. Yagoda, M. von Rechenberg, E. Zaganjor, A. J. Bauer, W. S. Yang, D. J. Fridman, A. J. Wolpaw, I. Smukste, J. M. Peltier, J. J. Boniface, R. Smith, S. L. Lessnick, S. Sahasrabudhe and B. R. Stockwell, Nature, 2007, 447, 864-868. 
4 S. Chen, J. T. Do, Q. Zhang, S. Yao, F. Yan, E. C. Peters, H. R. Schöler, P. G. Schultz and S. Ding, Proc. Natl. Acad. Sci. U. S. A., 2006, 103, 17266-17271.

5 J. R. W. Conway, N. O. Carragher and P. Timpson, Nat. Rev. Cancer, 2014, 14, 314-328.

6 G. J. Puppels, F. F. M. de Mul, C. Otto, J. Greve, M. RobertNicoud, D. J. Arndt-Jovin and T. M. Jovin, Nature, 1990, 347, 301-303.

7 W. Wang, J. Zhao, M. Short and H. Zeng, J. Biophotonics, 2015, 8, 527-545.

8 E. Ploetz, S. Laimgruber, S. Berner, W. Zinth and P. Gilch, Appl. Phys. B: Lasers Opt., 2007, 87, 389-393.

9 C. W. Freudiger, W. Min, B. G. Saar, S. Lu, G. R. Holtom, C. He, J. C. Tsai, J. X. Kang and X. S. Xie, Science, 2008, 322, 1857-1861.

10 C. W. Freudiger, W. Yang, G. R. Holtom, N. Peyghambarian, X. S. Xie and K. Q. Kieu, Nat. Photonics, 2014, 8, 153-159.

11 B. G. Saar, C. W. Freudiger, J. Reichman, C. M. Stanley, G. R. Holtom and X. S. Xie, Science, 2010, 330, 1368-1370.

12 Y. Shen, F. Xu, L. Wei, F. Hu and W. Min, Angew. Chem., Int. Ed., 2014, 53, 5596-5599.

13 L. Wei, Y. Yu, Y. Shen, M. C. Wang and W. Min, Proc. Natl. Acad. Sci. U. S. A., 2013, 110, 11226-11231.

14 L. Wei, Y. Shen, F. Xu, F. Hu, J. K. Harrington, K. L. Targoff and W. Min, ACS Chem. Biol., 2015, 10, 901-908.

15 P. Wang, B. Liu, D. Zhang, M. Y. Belew, H. A. Tissenbaum and J.-X. Cheng, Angew. Chem., Int. Ed., 2014, 53, 1178711792.

16 D. Fu, Y. Yu, A. Folick, E. Currie, R. V. Farese, T.-H. Tsai, X. S. Xie and M. C. Wang, J. Am. Chem. Soc., 2014, 136, 8820-8828.

17 F.-K. Lu, S. Basu, V. Igras, M. P. Hoang, M. Ji, D. Fu, G. R. Holtom, V. A. Neel, C. W. Freudiger, D. E. Fisher and X. S. Xie, Proc. Natl. Acad. Sci. U. S. A., 2015, 112, 1162411629.

18 X. Zhang, M. B. J. Roeffaers, S. Basu, J. R. Daniele, D. Fu, C. W. Freudiger, G. R. Holtom and X. S. Xie, ChemPhysChem, 2012, 13, 1054-1059.

19 W. J. Tipping, M. Lee, A. Serrels, V. G. Brunton and A. N. Hulme, Chem. Soc. Rev., 2016, 45, 2075-2089.

20 L. Wei, F. Hu, Z. Chen, Y. Shen, L. Zhang and W. Min, Acc. Chem. Res., 2016, 49, 1494-1502.

21 W. S. Chiu, N. A. Belsey, N. L. Garrett, J. Moger, M. B. Delgado-Charro and R. H. Guy, Proc. Natl. Acad. Sci. U. S. A., 2015, 112, 7725-7730.

22 J.-X. Cheng and X. S. Xie, Science, 2015, 350, aaa8870, DOI: 10.1126/science.aaa8870.

23 D. Fu, J. Zhou, W. S. Zhu, P. W. Manley, Y. K. Wang, T. Hood, A. Wylie and X. S. Xie, Nat. Chem., 2014, 6, 614-622.

24 H. Yamakoshi, K. Dodo, A. Palonpon, J. Ando, K. Fujita, S. Kawata and M. Sodeoka, J. Am. Chem. Soc., 2012, 134, 20681-20689.

25 S. Hong, T. Chen, Y. Zhu, A. Li, Y. Huang and X. Chen, Angew. Chem., Int. Ed., 2014, 53, 5827-5831.

26 L. Wei, F. Hu, Y. Shen, Z. Chen, Y. Yu, C.-C. Lin, M. C. Wang and W. Min, Nat. Methods, 2014, 11, 410-412.
27 H. Yamakoshi, A. F. Palonpon, K. Dodo, J. Ando, S. Kawata, K. Fujita and M. Sodeoka, Chem. Commun., 2014, 50, 13411343.

28 H. Yamakoshi, A. Palonpon, K. Dodo, J. Ando, S. Kawata, K. Fujita and M. Sodeoka, Bioorg. Med. Chem. Lett., 2015, 25, 664-667.

29 H. J. Lee, W. Zhang, D. Zhang, Y. Yang, B. Liu, E. L. Barker, K. K. Buhman, L. V. Slipchenko, M. Dai and J.-X. Cheng, Sci. Rep., 2015, 5, 7930.

30 H. Yamakoshi, K. Dodo, M. Okada, J. Ando, A. Palonpon, K. Fujita, S. Kawata and M. Sodeoka, J. Am. Chem. Soc., 2011, 133, 6102-6105.

31 S. F. El-Mashtoly, D. Petersen, H. K. Yosef, A. Mosig, A. Reinacher-Schick, C. Kotting and K. Gerwert, Analyst, 2014, 139, 1155-1161.

32 A. Lucotti, M. Tommasini, D. Fazzi, M. Del Zoppo, W. A. Chalifoux, R. R. Tykwinski and G. Zerbi, J. Raman Spectrosc., 2012, 43, 1293-1298.

33 S. Eisler, A. D. Slepkov, E. Elliott, T. Luu, R. McDonald, F. A. Hegmann and R. R. Tykwinski, J. Am. Chem. Soc., 2005, 127, 2666-2676.

34 J. Y. Lee, S. B. Suh and K. S. Kim, J. Chem. Phys., 2000, 112, 344-348.

35 T. Luu, E. Elliott, A. D. Slepkov, S. Eisler, R. McDonald, F. A. Hegmann and R. R. Tykwinski, Org. Lett., 2005, 7, 5154.

36 S. M. E. Simpkins, M. D. Weller and L. R. Cox, Chem. Commun., 2007, 4035-4037.

37 S. Szafert and J. A. Gladysz, Chem. Rev., 2003, 103, 41754205.

38 I. A. Inverarity and A. N. Hulme, Org. Biomol. Chem., 2007, 5, 636-643.

39 I. A. Inverarity, R. F. H. Viguier, P. Cohen and A. N. Hulme, Bioconjugate Chem., 2007, 18, 1593-1603.

40 E. M. Rosser, S. Morton, K. S. Ashton, P. Cohen and A. N. Hulme, Org. Biomol. Chem., 2004, 2, 142-149.

41 C. A. Lipinski, F. Lombardo, B. W. Dominy and P. J. Feeney, Adv. Drug Delivery Rev., 1997, 23, 3-25.

42 T. Zhu, S. Cao, P.-C. Su, R. Patel, D. Shah, H. B. Chokshi, R. Szukala, M. E. Johnson and K. E. Hevener, J. Med. Chem., 2013, 56, 6560-6572.

43 M. C. Wenlock, MedChemComm, 2016, 7, 706-719.

44 M. Macías-Silva, G. Vázquez-Victorio and J. HernándezDamián, Curr. Chem. Biol., 2010, 4, 124-132.

45 S. Morton, R. J. Davis, A. McLaren and P. Cohen, EMBO J., 2003, 22, 3876-3886.

46 Z. Chen, T. B. Gibson, F. Robinson, L. Silvestro, G. Pearson, B. Xu, A. Wright, C. Vanderbilt and M. H. Cobb, Chem. Rev., 2001, 101, 2449-2476.

47 D. Monaghan, E. O'Connell, F. L. Cruickshank, B. O'Sullivan, F. J. Giles, A. N. Hulme and H. O. Fearnhead, Biochem. Biophys. Res. Commun., 2014, 443, 761-767.

48 A. Mingo-Sion, P. M. Marietta, E. Koller, D. M. Wolf and C. L. Van Den Berg, Oncogene, 2004, 23, 596-604.

49 Y. Liu, Y. Wang, W. Li, P. Zheng and Y. Liu, Cancer Res., 2009, 69, 5954-5960. 
50 H. Heidari Torkabadi, C. R. Bethel, K. M. Papp-Wallace, P. A. J. de Boer, R. A. Bonomo and P. R. Carey, Biochemistry, 2014, 53, 4113-4121.

51 L. Opilik, T. Schmid and R. Zenobi, Annu. Rev. Anal. Chem., 2013, 6, 379-398.

52 M. Lee, A. Downes, Y.-Y. Chau, B. Serrels, N. Hastie, A. Elfick, V. Brunton, M. Frame and A. Serrels, IntraVital, 2015, 4, e1055430.

53 Z. Movasaghi, S. Rehman and I. U. Rehman, Appl. Spectrosc. Rev., 2007, 42, 493-541.

54 Z. Yu, T. Chen, X. Zhang, D. Fu, X. Liao, J. Shen, X. Liu, B. Zhang, X. S. Xie, X.-D. Su, J. Chen and Y. Huang, Chem. Sci., 2012, 3, 2646-2654.

55 D. Zhang, M. N. Slipchenko, D. E. Leaird, A. M. Weiner and J.-X. Cheng, Opt. Express, 2013, 21, 13864-13874.

56 B. Isherwood, P. Timpson, E. J. McGhee, K. I. Anderson, M. Canel, A. Serrels, V. G. Brunton and N. O. Carragher, Pharmaceutics, 2011, 3, 141-170.

57 A. M. Bogdanov, E. I. Kudryavtseva and K. A. Lukyanov, PLoS One, 2012, 7, e53004.

58 P. D. Chowdary, Z. Jiang, E. J. Chaney, W. A. Benalcazar, D. L. Marks, M. Gruebele and S. A. Boppart, Cancer Res., 2010, 70, 9562-9569.
59 F.-K. Lu, D. Calligaris, O. I. Olubiyi, I. Norton, W. Yang, S. Santagata, X. S. Xie, A. J. Goldby and N. Y. R. Agar, Cancer Res., 2016, 76, 3451-3462.

60 A. Pol, S. P. Gross and R. G. Parton, J. Biol. Chem., 2014, 204, 635-646.

61 C. Zhang, J. Li, L. Lan and J.-X. Cheng, Anal. Chem., 2017, 89, 4502-4507.

62 A. Salic and T. J. Mitchison, Proc. Natl. Acad. Sci. U. S. A., 2008, 105, 2415-2420.

63 J. Jia, F. Zhu, X. Ma, Z. Cao, Y. Li and Y. Z. Chen, Nat. Rev. Drug Discovery, 2009, 8, 111-128.

64 B. Al-Lazikani, U. Banerji and P. Workman, Nat. Biotechnol., 2012, 30, 679-692.

65 J. E. Dancey and H. X. Chen, Nat. Rev. Drug Discovery, 2006, 5, 649-659.

66 J. C. Dawson and N. O. Carragher, Front. Pharmacol., 2014, 5, 118.

67 Z.-M. Zhang, S. Chen, Y.-Z. Liang, Z.-X. Liu, Q.-M. Zhang, L.-X. Ding, F. Ye and H. Zhou, J. Raman Spectrosc., 2010, 41, 659-669. 